International Journal of Health Sciences
Available online at www.sciencescholar.us
Vol. 6 No. 1, April 2022, pages: 255-266
e-ISSN: 2550-696X, p-ISSN: 2550-6978
https://doi.org/10.53730/ijhs.v6n1.3988

\title{
Formation of Student Professional Skills under Pandemic Conditions
}

\author{
(1) CrossMark
Serhii Kubitskyi a, Kateryna Pavelkiv b, Iryna Yatsyk c, Olexandr Kryvonos d, Svitlana Tsymbal-Slatvinska ${ }^{\mathrm{e}}$

Manuscript submitted: 17 September 2021, Manuscript revised: 18 December 2021, Accepted for publication: 12 January 2022

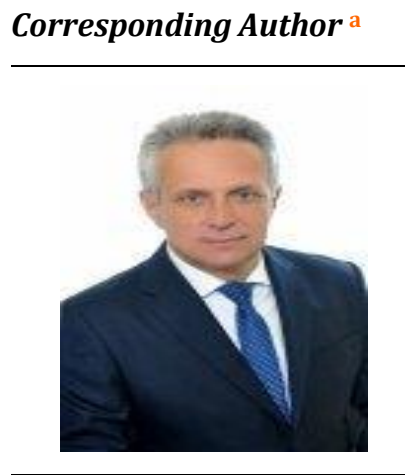

Keywords

educational process;

health care;

health crisis;

mental health;

nutrition;

pandemic restrictions;

professional skills;

vocational training;

\begin{abstract}
The study aims to analyze the process of developing students' professional skills and characterizing the degree of formation of this type of skill in the educational process during a pandemic. Methodology. In the course of the research, data from international studies and scientific publications have been used, as well as the results of students' and teachers' surveys on their position and development of professional skills of students during pandemic constraints of the educational process. Results. Through the methods of questioning, the pros and cons of distance learning from the point of view of degree-seeking students have been revealed, which is important for the formation of a studentoriented model of higher education. Advantages of distance learning include as follows: a flexible learning schedule, compatibility of work and study, mastering additional skills, courses, hobbies, and increasing motivation for independent learning. Disadvantages of distance learning during a pandemic are as follows: technical problems, lack of Internet access, the difficulty of self-study, low level of information technology level proficiency among teachers and students. It has been determined that students and educators require additional support during the pandemic.
\end{abstract}

\section{Contents}

Abstract

1 Introduction.

2 Materials and Methods

\footnotetext{
${ }^{a}$ National University of Life and Environmental Sciences of Ukraine, Kyiv, Ukraine

b Rivne State University of the Humanities, Rivne, Ukraine

c Zhytomyr Ivan Franko State University, Zhytomyr, Ukraine

d Zhytomyr Ivan Franko State University, Zhytomyr, Ukraine

e Pavlo Tychyna Uman State Pedagogical University, Uman, Ukraine
} 


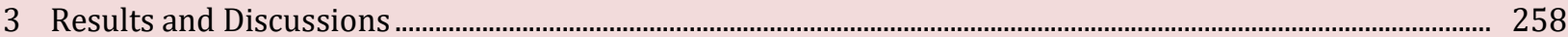

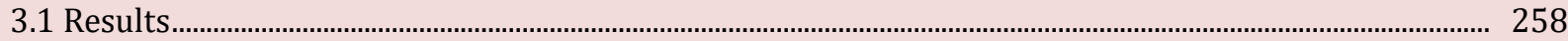

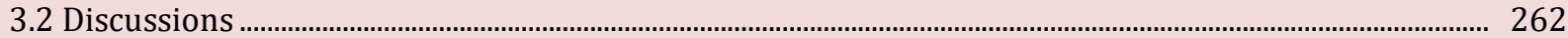

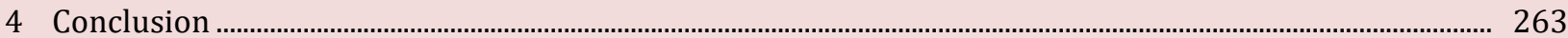

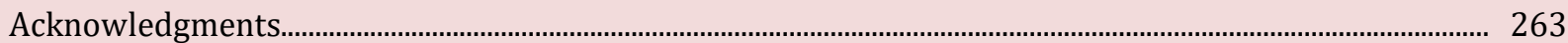

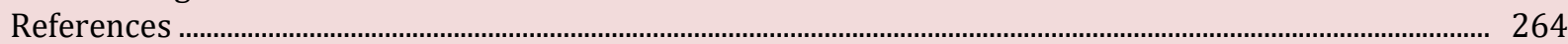

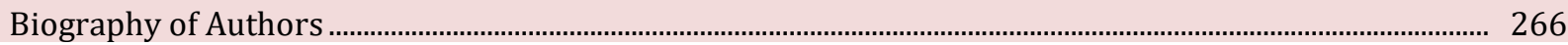

\section{Introduction}

The relevant issue raised in the present academic paper is due to the need of modern society for highly qualified and competitive specialists who are ready to face the challenges of the modern world in the context of the COVID-19 pandemic. In this context, the present research complements and deepens the methodological knowledge for the training of future specialists in various fields for their effective professional activities (GfK Ukraine (Project), 2017).

Approaches and models to the organization and management of education, as always in the history of pedagogy and philosophy of education, have been, are, and will be a reflective projection of the prevailing processes in society (Imanova, 2021). In modern realities, teachers should resort to new ways of managing the learning process to provide productive work, which in turn forces them to comply with the new rules of pedagogical management (Bakhov et al., 2021).

In the light of new definitions, pedagogical management can be interpreted as a set of principles, methods, means, that is, optimizing human, material, and financial resources to achieve maximum results (Bloom, 2018). The scientific work lies in the fact that teachers currently are forced to resort to new methods, means, and forms of teaching, forasmuch as the old ones, previously known and well-studied, cannot fully satisfy the educational needs of progressive youth (Mukhtar et al., 2020).

\section{Literature review}

The subject of publications on trends in the development of education mainly relates to the following topics, namely: online learning; internationalization of education (Oleshko \& Rovnyagin 2020). Even during pandemic lockdowns, college teachers and professors who have struggled with digitalization in education, job cuts, and wage cuts have realized that must be protected. Structural lighthouses of support for teachers are as follows: retention of employment and wages; security and well-being, health care; participation in the development of educational policy in response to the challenges of COVID-19; providing appropriate professional support, training, and education; creating fair working conditions and developing tools for supporting educators, promoting their social and emotional competence (UNESCO, 2020b; UNESCO, 2019).

In general, the pandemic will negatively affect higher education in the future, and the theoretical and empirical assumptions of scientists are the scientific basis for further research (Brammer \& Clark, 2020). According to the viewpoint of S. Brammer, as society changes, so does the educational culture (Brammer \& Clark, 2020). M. Aboobacker, R. Pulikkottil, K. Praveenlal believe that professional readiness is a purposeful result of profile vocational training and the formation of readiness for work, the ability to perform tasks, and the acquisition of self-education skills (Aboobacker et al., 2020).

The same definition is also given by E. Southgate, according to which professional readiness is a state of activity of the individual ensuring work efficiency (Boahin \& Hofman, 2014; Francescato et al., 2007). The desire of the teacher is determined by his attitude to his knowledge and the desire to improve the existing pedagogical and psychological skills. And abilities, in turn, constitute the person's competence, the totality of knowledge and skills necessary for the effective professional activity (Southgate, 2020).

V. Kukharenko and V. Bondarenko also adhere to this viewpoint, noting that competence is the ability of a person to perform specific labor functions (Kukharenko \& Bondarenko, 2020). In other words, the fact that a person knows that he is ready to engage in certain activities does not mean that he is capable of engaging in any profession (Jacob, 2020; Nugroho et al., 2021). The innovative direction of pedagogical action is determined by social-economic changes that require appropriate updating of educational policy, the readiness 
of teachers to learn and apply pedagogical innovations. Innovation is an idea that is applied for the first time and qualitatively changes the previous state of the system or process in which it is implemented (Martyushev et al., 2021).

According to the UNESCO Annual Report 2019, the current educational crisis will increase educational inequality around the world. Inequality is one of the top priorities for all education policymakers and professionals. It is expected that changes in the work of educational institutions will cause disproportionate damage to vulnerable and socially disadvantaged students/graduate students who rely on these institutions, counting on the provision of many social services, in particular, education, access to science, and health care and nutrition. Although the situation in the south of the global region is much more critical, there are many countries in the global north, including European countries that will also face these deepening negative crises (Matvienko-Sikar et al., 2021; Hugelius et al., 2021). Based on the mobility of people and ideas, proceeding from the ideas of infinity and unity, in the education systems of the EU countries, researchers identify such challenges caused, namely:

- There was no coherent and intergovernmental policy in the field of health and medicine;

- There was neither general financial and economic response nor agreement on the issuance of Eurobonds;

- Tackling Europe's worst health crisis has been a national challenge, as it has been for decades;

- Even though the closure of educational institutions is a reality in most European countries, the reaction of EU institutions and structures is still limited to providing educational materials online (UNESCO, 2020a).

This assumption is supported by A. Artyukhov, who clarifies that the crisis is much more than just the possibility of a rapid transition from physical to an online educational environment, given the fact that:

- Existing problems of homeschooling of teachers, educators, heads of institutions, parents, and students;

- The issue of the role, interests, and participants of digital educational platforms requires investigation;

- Threats to civil liberties arise through quarantine and various social and communication blockages;

- Threats to academic mobility and investigations are observed;

- The mental health of children, adolescents, parents and teachers, educators are deteriorating;

- The conditions for the social development of children and youth are changing (taking into account the need for long physical distances);

- The threats of hunger and domestic violence that many children and young people face are becoming real;

- Special problems for young people and displaced children in Europe who need isolation (in homes and other shelters they may not even have) need to be addressed);

- There are problems with teachers' adaptation to online teaching (Artyukhov, 2021).

As Berezhna S. and Prokopenko note in their study, "in the next 5 years, the growing demand for online education will only grow; in 20-30 years we will actively use augmented reality technologies and other innovations in distance education" (Prokopenko \& Berezhna, 2020). Therefore, taking into account psychological features when designing the educational process under the conditions of distance learning is an important psychological and pedagogical task, the solution of which will help increase independence and ownership. Indirect communication becomes enjoyable and learning becomes effective (Kukharenko \& Bondarenko, 2020; Estevez et al., 2019).

Thus, the rapid development of social-economic requirements for the profession, the need for psychological assistance requires significant changes in the system of training future specialists. The purpose of the research lies in analyzing the features of professional training of students, problems, and prospects for optimizing the educational process under the conditions of the pandemic (Van der Berg, 2008; Yew \& Goh, 2016).

Kubitskyi, S., Pavelkiv, K., Yatsyk, I., Kryvonos, O., \& Tsymbal-Slatvinska, S. (2022). Formation of student professional skills under pandemic conditions. International Journal of Health Sciences, 6(1), 255-266. https://doi.org/10.53730/ijhs.v6n1.3988 


\section{Materials and Methods}

Vocational training of students under the conditions of the pandemic was based on a survey of full-time students of higher educational institutions located in Kyiv (Kyiv National Economic University, Igor Sikorsky Kyiv Polytechnic Institute, National Aviation University). The study was conducted in the 2019-2021 academic year. 182 students of technical and humanitarian specialties and 88 teachers of higher educational institutions took part in the survey. In particular, the questionnaire includes questions concerning:

- Assessment of the level of knowledge until 2019 and in the conditions of distance learning during the quarantine period;

- Shortcomings of distance learning regarding the quality of knowledge;

- Aspects where it is necessary to optimize the working conditions of teachers.

Respondents were asked to determine the score for each of the indicators from 1 to 100 , and then the average score per respondent was calculated. Figure 1. This is an example of a figure.

\section{Results and Discussions}

\subsection{Results}

A survey of students showed that the quality of skills acquired in the pre-pandemic period and during quarantine according to the subjective assessments of students are as follows (Figure 1).

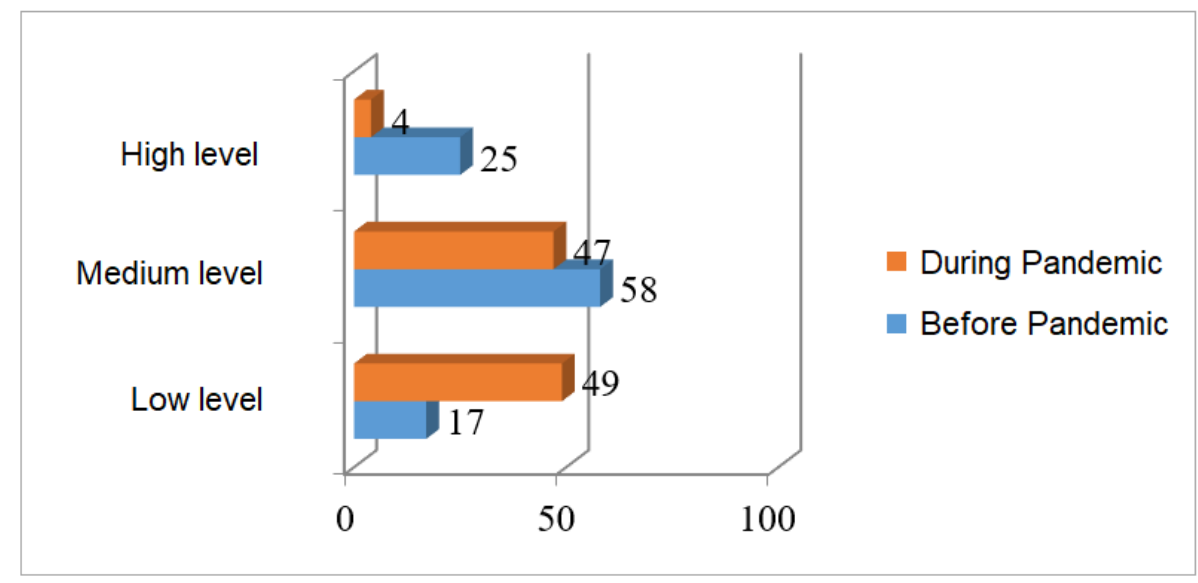

Figure 1. The general assessment of the level of professional competence by students of HEIs, \%

The following answers were given to the questions concerning the assessment of the general efficiency level of the process of developing professional competencies, assessment of the efforts made during the educational process to acquire knowledge, and readiness to work in the specialty obtained (Figure 2). 


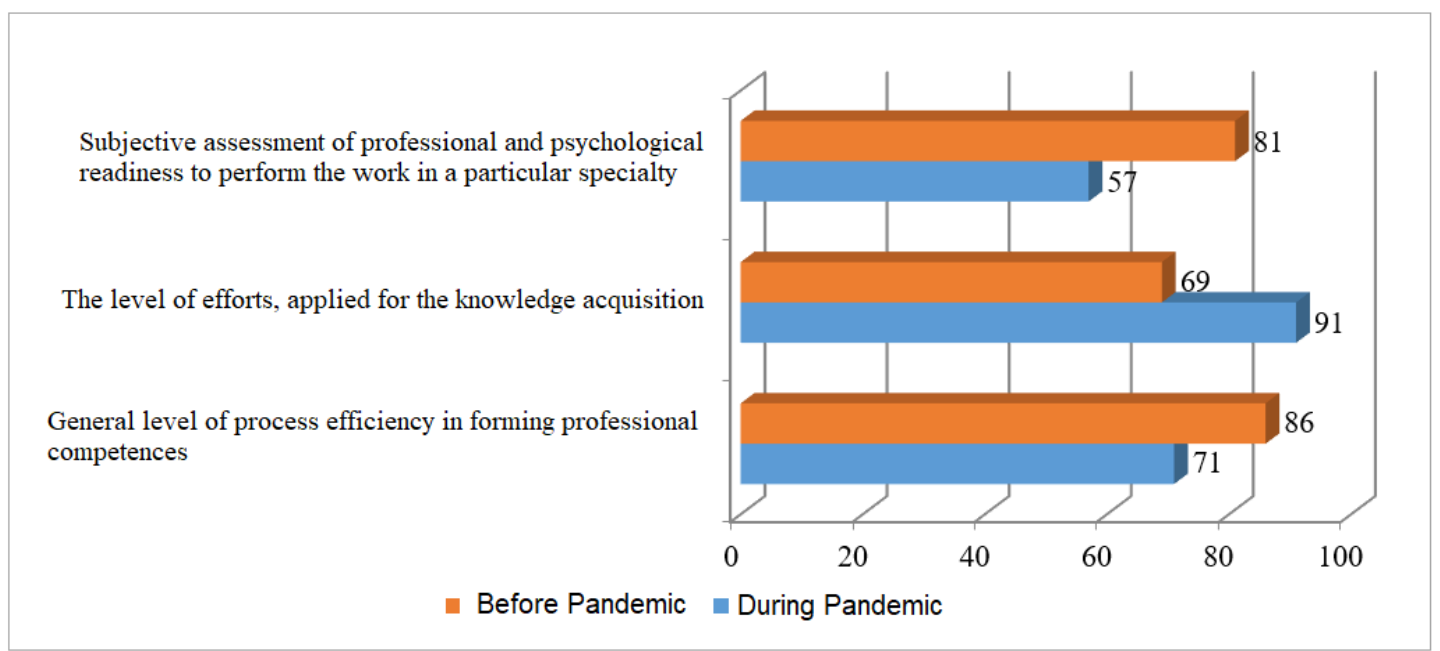

Figure 2. Subjective assessment of the degree-seeking students' indicators of the level of knowledge acquired before 2019 and in terms of distance learning during quarantine, \%

Experience a general decline in their level of competence in the knowledge gained from $81 \%$ to $51 \%$ during the pandemic compared to previous years. At the same time, according to students' assessments, $22 \%$ more effort is spent on knowledge acquisition than before.

Particular attention is drawn to the characteristic of the effectiveness of the process of forming competencies. It should be emphasized that the assessment of this indicator was, in contrast to others, quite heterogeneous: many students assessed the effectiveness of the learning process above $90 \%$, while due to a large number of low grades the average decreased from $86 \%$ to $71 \%$. Respondents referred to the following aspects to the advantages of distance learning (Figure 3):

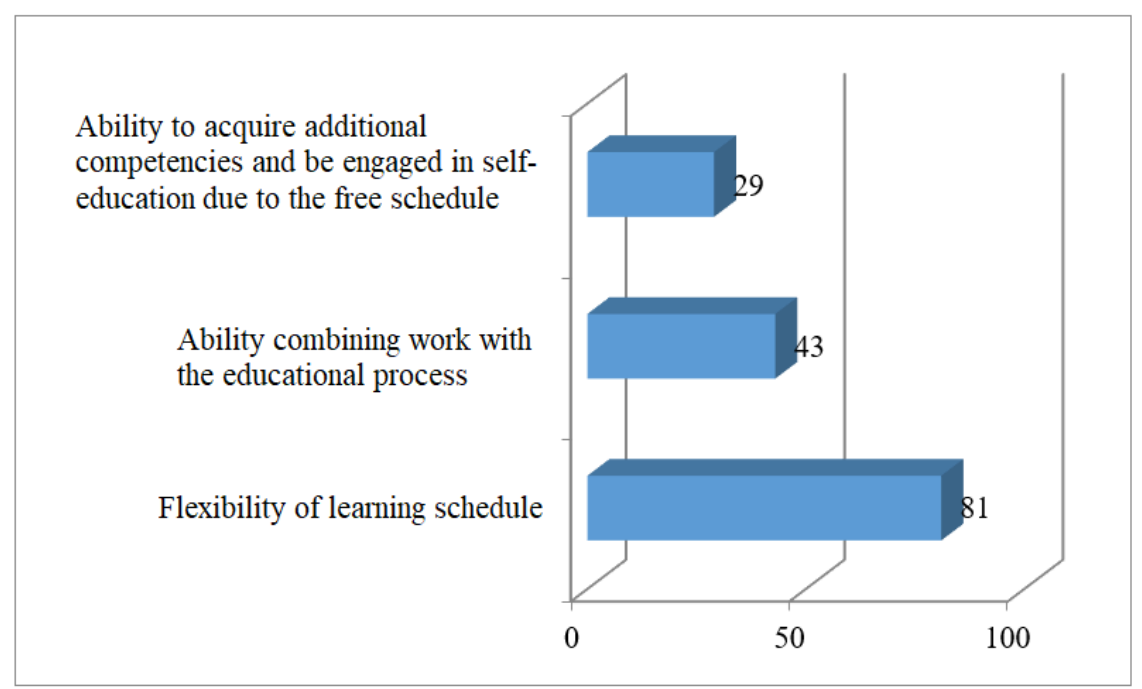

Figure 3. Advantages of distance learning from the point of view of students, $\%$

As it can be seen from Figure 3, students consider the flexibility of the learning schedule to be the primary advantage of distance learning, which provides an opportunity for them to freely plan their own time, freeing

Kubitskyi, S., Pavelkiv, K., Yatsyk, I., Kryvonos, O., \& Tsymbal-Slatvinska, S. (2022). Formation of student professional skills under pandemic conditions. International Journal of Health Sciences, 6(1), 255-266. https://doi.org/10.53730/ijhs.v6n1.3988 
it up for travel and leisure. Conspicuous is the fact that, on average, this factor was estimated by respondents at $81 \%$.

From the point of view of degree-seeking students, a free study schedule is rather important, allowing them to free up time to participate in additional educational programs or work, combining work with the educational process; the respondents rated this opportunity at $43 \%$, which is also a high indicator. A positive and unexpected result of the survey is a significant percentage of importance for students $(29 \%)$ ready to acquire additional competencies and be engaged in self-education due to the free schedule at the main place of study.

At the same time, such advantages as mastering additional resources during distance learning, the possibility of additional communication by students gained a total of less than $1 \%$. The shortcomings of distance learning during the pandemic, outlined by respondents - degree-seeking students, are represented in Figure 4 (Figure 4):

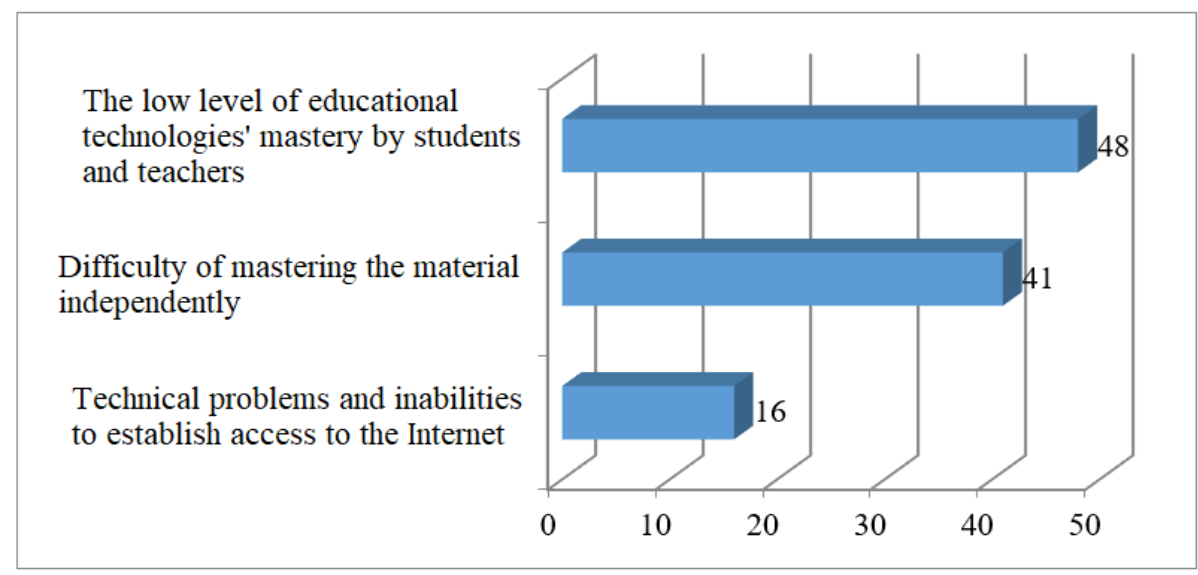

Figure 4. Disadvantages of distance learning during the pandemic from the point of view of degree-seeking students, \%

As it can be seen from Figure 4, significant difficulties in the process of acquiring knowledge for students are the low level of mastery of educational technologies (on average, students rated the importance of this barrier to education by $48 \%$ ) and the difficulty of mastering the material independently (41\%). Among other degreeseeking students, difficulties related to technical problems and inabilities to establish access to the Internet were highlighted (16\%). As the teachers of higher educational institutions noted in their answers (Figure 5):

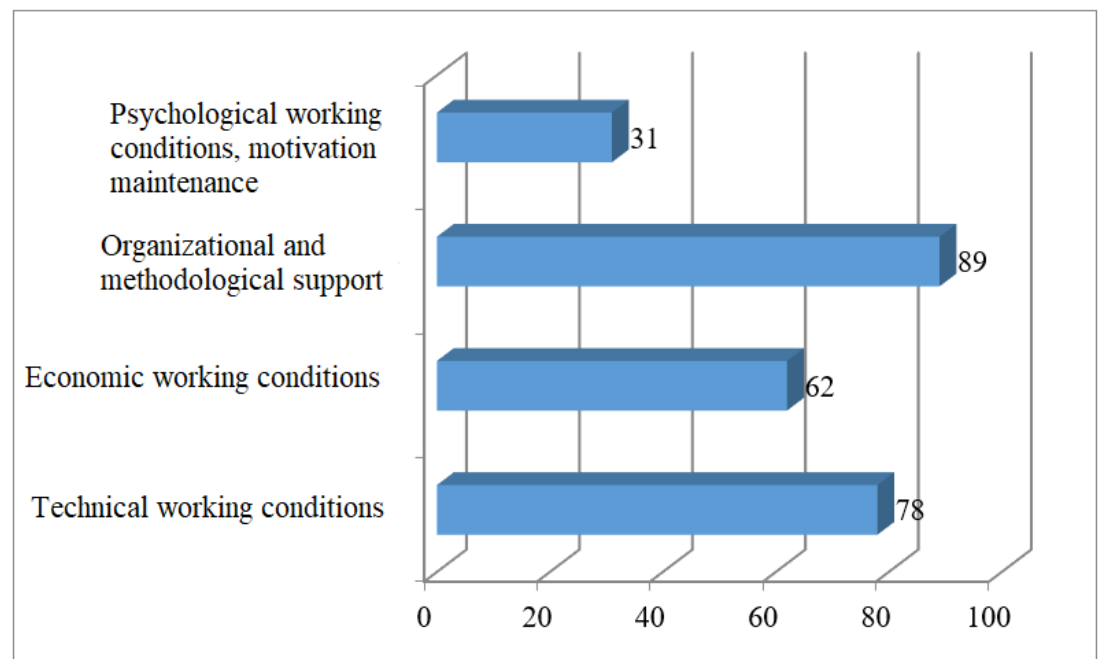

Figure 5. Subjective assessment of areas by teachers of HEIs that need to optimize working conditions, \% 
As it can be seen from Figure 5, teachers specified low organizational and methodological support, as well as unsatisfactory technical working conditions, as priority issues that need to be addressed to improve the quality of students' professional skills. Students, as well as scientists and teachers, faced the challenges of quick adaptation to the pandemic (Figure 6):

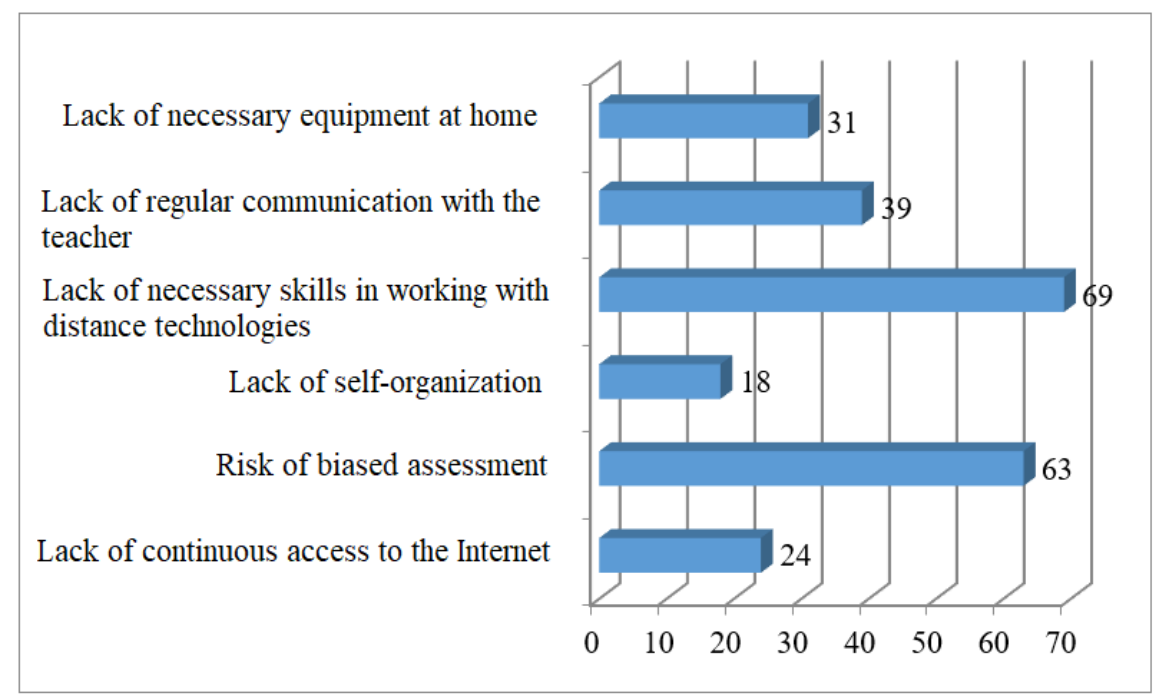

Figure 6. Difficulties of distance learning from the point of view of students, $\%$

As it can be seen from Figure 6, according to the viewpoints of degree-seeking students, the biggest obstacles to ensuring a quality learning process were the lack of necessary skills in working with technology and distance technology and the risk of biased assessment. Difficulties of distance learning are as follows (Figure 7):

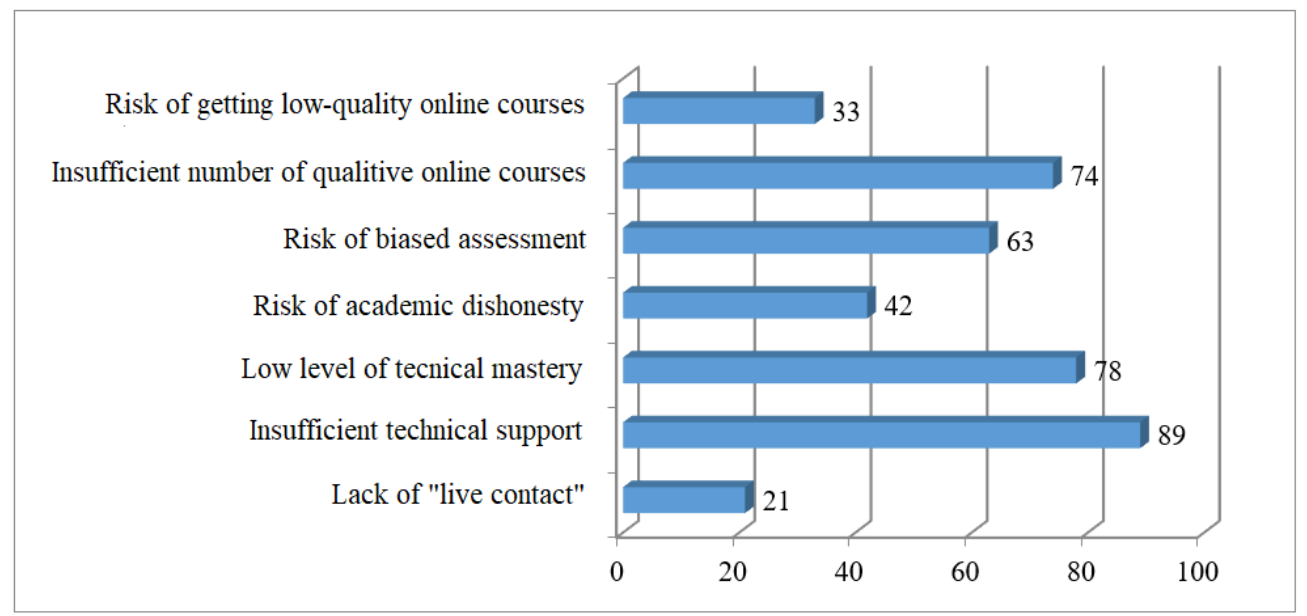

Figure 7. Difficulties of distance learning from scientific workers, \%

According to a survey conducted, the teachers note the most significant difficulties they had to face in the process of distance learning as follows: insufficient technical support for the educational process, low level of mastery of hardware and software, as well as the lack or an insufficient number of online courses and resources that they could master on their own and use in the learning process.

Kubitskyi, S., Pavelkiv, K., Yatsyk, I., Kryvonos, O., \& Tsymbal-Slatvinska, S. (2022). Formation of student professional skills under pandemic conditions. International Journal of Health Sciences, 6(1), 255-266. https://doi.org/10.53730/ijhs.v6n1.3988 


\subsection{Discussions}

Thus, according to investigations conducted by S. Brammer and T. Clark, online education is a viable and effective learning strategy (Brammer \& Clark 2020; Kardina et al., 2020). This conclusion of scientists is based on the fact that, by its definition, online education involves regular face-to-face communication between teachers and students, forasmuch as it is used together with other strategies as a method of blended learning and is intended to be used in combination with other various personal training methods. Along with this, A. Oleshko and O. Rovnyagin have rightly noted that there are objective problems that may arise when using online education in Ukraine, namely:

- Slow development of high-speed mobile Internet;

- Lack of innovative thinking among teachers of traditional universities;

- Subventions for state educational institutions;

- Insufficient experience of potential teachers in developing courses/programs;

- Lack of methodological apparatus and practice of distance education;

- Lack of investments in online education.

These scholars, in particular, emphasize the government's long-term disregard for online education opportunities for distance and inclusive learning (Oleshko \& Rovnyagin, 2021). The opportunities for the development of online education in Ukraine include as follows:

- Inclusive education in educational institutions can be activated through online platforms;

- Integration of rural areas and small towns and youth from such settlements into the general processes of development of education and science, technology and communication, the creation of a "social lift" for talented youth;

- The emergence of new specializations and personnel training in those areas where there is a lack of literature and academic knowledge;

- Conducting training for the diaspora and Ukrainian scholars abroad based on domestic higher educational institutions.

Financial and legal aid on the part of government agencies and large corporations is important to support these initiatives, as well as the willingness of teachers to promote online education and students - to promote educational motivation. Modern vocational education poses new challenges to the domestic higher education system (Slipchuk et al., 2021). In connection with the economic and social-cultural integration of European and international society, the development of market relations, the increasing complexity of the structure of the current social-economic situation in the context of the COVID-19 pandemic, there is a growing need to train specialists capable of more responsible and competent professionalism (Downar et al., 2010; Vecchio et al., 2020). Consequently, increasing the need for training specialists is an important educational issue (Barzylovych et al., 2020; Widana et al., 2021).

Vocational training is part of an organized pedagogical process of acquiring professional knowledge, skills, and abilities, which is implemented within the relevant industry-standard cycle. We share the opinion of S. Berezhna and I. Prokopenko that the training of "qualified competitive personnel with a high level of professional knowledge" (Prokopenko \& Berezhna, 2020).

The statement of V. Kukharenko and V. Bondarenko is reasonably accurate in this regard, according to which, to ensure the optimal educational process, an effective pedagogical system of preparing the student for future activities is necessary, the core of which should be the achievement of the psychological maturity of the individual, the formation of the student's comprehensive readiness for personal and professional selffulfillment (Böhn \& Deutscher, 2022; Olivos et al., 2016). The content, forms, methods, and functioning of the learning process should be subordinated to the general goal of forming the personality of the future specialist, taking into account his individual and typological features during training at higher educational institutions (Kukharenko \& Bondarenko, 2020).

It should be reminded that, according to the recommendations of the European Commission, the pedagogical system of training future professionals is a set of organizational structures, management actions, 
specific principles, content, methods, forms of organization, and various means of forming psychological readiness and professional qualities of students, methods and evaluation criteria, their personal, professional qualities and readiness for future professional activity (European Commission, 2022).

Thus, the self-educational competence of future professionals is intensively formed through the pronounced motivation of students towards professional development and the proper organization of vocational training through the introduction of pedagogical incentives and participation in research activities (Diachenko et al., 2021). The conducted research has made it possible to establish that students need to realize their own and social content of education, gain skills to work with their values, motivation and internal need for systematic learning, knowledge, development of emotional and volitional mechanisms to overcome difficulties and, in addition, master the skills of self-education. The survey has also proved that one of the priority areas for the work of state authorities on the development of education during the pandemic should be educational programs for teachers, which will ensure their mastery of technical and software tools to participate in the educational process to provide students with equal opportunities for high-quality education.

\section{Conclusion}

The research has revealed that modern conditions indicate the need for specialists in the sphere of economics who have a wide range of deep knowledge and skills. Due to the influence of COVID-19, the higher education system needs to be transformed and adapted to new conditions. Adaptation of students and teachers to the specifics of distance learning requires the acquisition of technical and other related skills. Future professionals should improve their skills, master new online courses, and programs that take into account the features of distance learning. State authorities dealing with the problem of distance education should create appropriate conditions for uninterrupted and high-quality access of students to the Internet, especially in rural areas.

In modern conditions, to ensure an effective educational process and the acquisition of general and professional competencies of the higher education program, it is necessary to fully combine the potential of the state authorities, higher educational institutions, and public and student organizations. Particular attention should be paid to improving the technical, economic, and organizational working conditions, motivation of the research, and teaching staff for ensuring their quality professional activities. Along with this, the research does not cover all aspects of this problem; consequently, further prospects in the study will be directed on studying integration content for students under conditions distance learning

Acknowledgments

We are grateful to two anonymous reviewers for their valuable comments on the earlier version of this paper.

Kubitskyi, S., Pavelkiv, K., Yatsyk, I., Kryvonos, O., \& Tsymbal-Slatvinska, S. (2022). Formation of student professional skills under pandemic conditions. International Journal of Health Sciences, 6(1), 255-266. https://doi.org/10.53730/ijhs.v6n1.3988 


\section{References}

Aboobacker, M., Pulikkottil, R., \& Praveenlal, K. (2020). The Pedagogical Shift During COVID 19 Pandemic: Online Medical Education, Barriers and Perceptions in Central Kerala. Journal of Medical Education and Curricular Development, 7, 1-4.

Artyukhov, A. A. (2021). Some Aspects Of Theory And Practice Of The Organization Of" Distance Learning" When Studying Geography At The Basic School. International research journal, (5), 51.

Bakhov, I., Opolska, N., Bogus, M., Anishchenko, V., \& Biryukova, Y. (2021). Emergency Distance Education in the Conditions of COVID-19 Pandemic: Experience of Ukrainian Universities. Education Sciences, 11(7), 364.

Barzylovych, A., Oliinyk, Y., Kostitska, I., Shakhman, N., \& Buryk, Z. (2020). Transformation of the Social and Medical Spheres under the Conditions of COVID-19. Systematic Reviews in Pharmacy, 11(11), 1328-1337.

Bloom, E. (2018). 7 key factors of successful digital transformation in the enterprise, 7.

Boahin, P., \& Hofman, W. A. (2014). Perceived effects of competency-based training on the acquisition of professional skills. International Journal of Educational Development, 36, 81-89. https://doi.org/10.1016/j.ijedudev.2013.11.003

Böhn, S., \& Deutscher, V. (2022). Dropout from initial vocational training-A meta-synthesis of reasons from the apprentice's point of view. Educational Research Review, 35, 100414. https://doi.org/10.1016/j.edurev.2021.100414

Brammer, S., \& Clark, T. (2020). COVID-19 and management education: Reflections on challenges, opportunities, and potential futures. British journal of Management, 31(3), 453.

Diachenko, A., Vusyk, H., Bielova, Y., Shurdenko, M., \& Titenko, O. (2021). The educational role in COVID-19 terms of ethnodesign graphic function in higher education practical activities. International Journal of Health Sciences, 5(3), 584-593. https://doi.org/10.53730/ijhs.v5n3.2540

Downar, J., Seccareccia, D., \& Associated Medical Services Inc. Educational Fellows in Care at the End of Life. (2010). Palliating a pandemic:"all patients must be cared for".Journal of pain and symptom management, 39(2), 291-295. https://doi.org/10.1016/j.jpainsymman.2009.11.241

Estevez, G. A., Espinosa, A. H. R., \& Rodríguez, D. L. (2019). Design of intervention program for preventing of alcohol misuse in university students. International Journal of Health \& Medical Sciences, 2(1), 33-38.

European Commission (2021). Digital Technologies in Education.

Francescato, D., Mebane, M., Porcelli, R., Attanasio, C., \& Pulino, M. (2007). Developing professional skills and social capital through computer supported collaborative learning in university contexts. International journal of human-computer studies, 65(2), 140-152. https://doi.org/10.1016/j.ijhcs.2006.09.002

GfK Ukraine (Project) (2017). Regional office of the Foundation. Friedrich Ebert in Ukraine, New Europe Center. GfK Ukraine.

Hugelius, K., Harada, N., \& Marutani, M. (2021). Consequences of visiting restrictions during the COVID-19 pandemic: An integrative review. International journal of nursing studies, 121, 104000. https://doi.org/10.1016/j.ijnurstu.2021.104000

Imanova, S. (2021). Promoting Azerbaijani Students' Intercultural Competence through Distance Education of Foreign Languages. Arab World English Journal (AWEJ) Volume, 12.

Jacob, J. U. U., \& Ensign, M. (2020). A brief social history of education in Nigeria. In Transactional radio instruction (pp. 1-17). Palgrave Macmillan, Cham.

Kardina, I., Ramadany, S., Sanusi B, Y., Made, S., Stang, S., \& Syarif, S. (2020). Children's midwifery learning media application about android-based rough motor development in improving midwifery student skills. International Journal of Health \& Medical Sciences, 3(1), 146-152.

Kukharenko, V. \& Bondarenko, V. (2020). Emergency distance learning in Ukraine. Collective monograph. Kharkiv.

Martyushev, N., Shutaleva, A., Malushko, E., Nikonova, Z., \& Savchenko, I. (2021). Online Communication Tools in Teaching Foreign Languages for Education Sustainability. Sustainability, 13(19), 11127.

Matvienko-Sikar, K., Pope, J., Cremin, A., Carr, H., Leitao, S., Olander, E. K., \& Meaney, S. (2021). Differences in levels of stress, social support, health behaviours, and stress-reduction strategies for women pregnant before and during the COVID-19 pandemic, and based on phases of pandemic restrictions, in Ireland. Women and Birth, 34(5), 447-454. https://doi.org/10.1016/j.wombi.2020.10.010 
Mukhtar, K., Javed, K., Arooj, M., \& Sethi, A. (2020). Advantages, Limitations and Recommendations for online learning during COVID-19 pandemic era. Pakistan journal of medical sciences, 36(COVID19-S4), S27.

Nugroho, A., Ilmiani, D., \& Rekha, A. (2021). EFL teachers' challenges and insights of online teaching amidst global pandemic. Metathesis: Journal of English Language, Literature, and Teaching, 4(3), 277-291.

Oleshko, A. \& Rovnyagin, O. (2021). Improving distance learning in higher education in pandemic constraints. Public administration: improvement and development, 1.

Oleshko, A., \& Rovnyagin, A. (2020). Anti crisis policy of national states in the context of overcoming the social and economic consequences of covid 19. Efektyvna ekonomika, 4.

Olivos, P., Santos, A., Martín, S., Cañas, M., Gómez-Lázaro, E., \& Maya, Y. (2016). The relationship between learning styles and motivation to transfer of learning in a vocational training programme. Suma Psicológica, 23(1), 25-32. https://doi.org/10.1016/j.sumpsi.2016.02.001

Prokopenko, I., \& Berezhna, S. (2020). Higher education institutions in Ukraine during the coronavirus, or COVID-19, outbreak: new challenges vs new opportunities.

Slipchuk, V., Yuzkiv, H., Batechko, N., Pisotska, M., \& Klymenko, L. (2021). Academic mobility development among university students during COVID-19 pandemic. International Journal of Health Sciences, 5(3), 573583. https://doi.org/10.53730/ijhs.v5n3.2490

Southgate, E. (2020). Using screen capture video to understand learning in virtual reality. In 2020 IEEE Conference on Virtual Reality and 3D User Interfaces Abstracts and Workshops (VRW) (pp. 418-421). IEEE.

UNESCO (2019). Learning Cities respond to COVID-19.

UNESCO (2020a). Institute for Lifelong Learning. Annual Report 2019

UNESCO (2020b). Supporting teachers and education personnel during times of crisis.

Van der Berg, S. (2008). How effective are poor schools? Poverty and educational outcomes in South Africa. Studies in Educational Evaluation, 34(3), 145-154. https://doi.org/10.1016/j.stueduc.2008.07.005

Vecchio, S., Ramella, R., Drago, A., Carraro, D., Littlewood, R., \& Somaini, L. (2020). CoVID19 pandemic and people with opioid use disorder: innovation to reduce risk. Psychiatry research, 289, 113047. https://doi.org/10.1016/j.psychres.2020.113047

Widana, I.K., Sumetri, N.W., Sutapa, I.K., Suryasa, W. (2021). Anthropometric measures for better cardiovascular and musculoskeletal health. Computer Applications in Engineering Education, 29(3), 550561. https://doi.org/10.1002/cae.22202

Yew, E. H., \& Goh, K. (2016). Problem-based learning: An overview of its process and impact on learning. Health professions education, 2(2), 75-79. https://doi.org/10.1016/j.hpe.2016.01.004

Kubitskyi, S., Pavelkiv, K., Yatsyk, I., Kryvonos, O., \& Tsymbal-Slatvinska, S. (2022). Formation of student professional skills under pandemic conditions. International Journal of Health Sciences, 6(1), 255-266. 


\section{Biography of Authors}

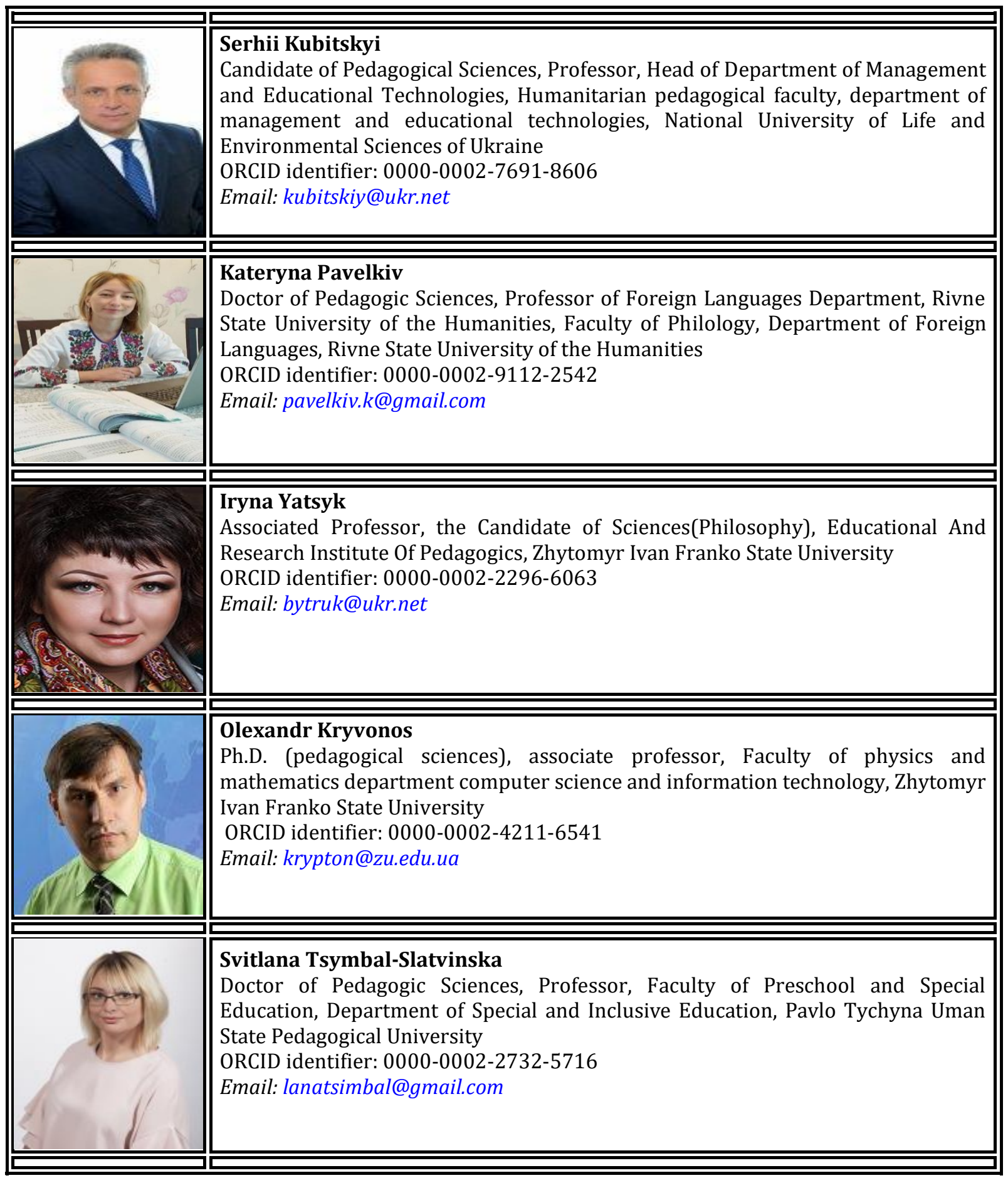

